\title{
PSYCHOLOGICA
}

\section{Contributo para o estudo psicométrico da versão portuguesa do Cuestionario de} Satisfacción Laboral S20/23

\author{
Autor(es): $\quad$ Ferreira, Joaquim Armando; Fernandes, Rosina; Santos, Eduardo \\ Ribeiro; Peiró, José Maria
}

Publicado por: Imprensa da Universidade de Coimbra

URL

persistente: URI:http://hdl.handle.net/10316.2/3462

DOI: DOI:http://dx.doi.org/10.14195/1647-8606_52-2_1

Accessed : $\quad$ 26-Apr-2023 13:08:50

A navegação consulta e descarregamento dos títulos inseridos nas Bibliotecas Digitais UC Digitalis, UC Pombalina e UC Impactum, pressupõem a aceitação plena e sem reservas dos Termos e Condições de Uso destas Bibliotecas Digitais, disponíveis em https://digitalis.uc.pt/pt-pt/termos.

Conforme exposto nos referidos Termos e Condições de Uso, o descarregamento de títulos de acesso restrito requer uma licença válida de autorização devendo o utilizador aceder ao(s) documento(s) a partir de um endereço de IP da instituição detentora da supramencionada licença.

Ao utilizador é apenas permitido o descarregamento para uso pessoal, pelo que o emprego do(s) título(s) descarregado(s) para outro fim, designadamente comercial, carece de autorização do respetivo autor ou editor da obra.

Na medida em que todas as obras da UC Digitalis se encontram protegidas pelo Código do Direito de Autor e Direitos Conexos e demais legislação aplicável, toda a cópia, parcial ou total, deste documento, nos casos em que é legalmente admitida, deverá conter ou fazer-se acompanhar por este aviso.

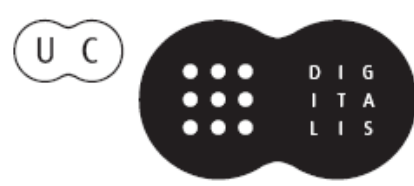




\section{NÚMERO 52}

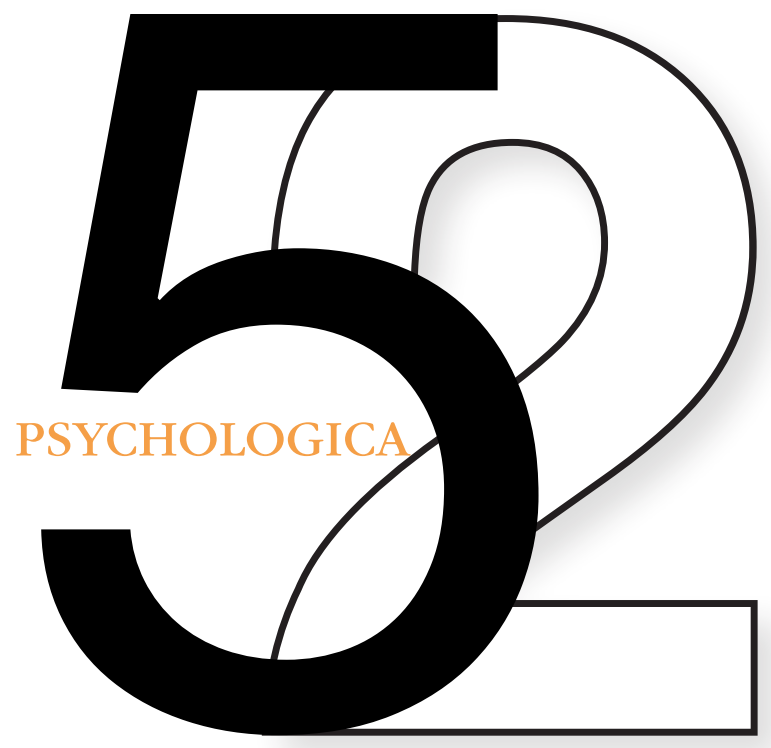

VOLUME II

IMPRENSA DA UNIVERSIDADE DE COIMBRA

FACULDADE DE PSICOLOGIA E DE CIÊNCIAS DA EDUCAÇÃo DA UNIVERSIDADE DE COIMBRA 


\section{Contributo para o estudo psicométrico da versão portuguesa do Cuestionario de Satisfacción Laboral $\mathrm{S} 2 \mathrm{O} / 23$}

Joaquim Armando Ferreira', Rosina Fernandes², Eduardo Ribeiro Santos ${ }^{3} \&$ José Maria Peiró 4

A satisfação com o trabalho é entendida como preponderante no binómio da produtividade da organização e da realização dos trabalhadores (Silva, 1998). A utilização de instrumentos que permitam avaliá-la em contexto nacional, tem vindo a ser alvo de alguns estudos, salientando-se a adaptação à população portuguesa do Cuestionario de Satisfacción Laboral S20/23 (Meliá \& Peiró, 1989a) efectuada por Pocinho e Garcia (2008).

Este trabalho constitui-se como mais um contributo para o estudo das qualidades psicométricas deste instrumento. Os resultados obtidos numa amostra de 136 trabalhadores portugueses, revelam que o questionário apresenta qualidades psicométricas satisfatórias ao nível da consistência interna (.95), da estabilidade temporal e da validade convergente (correlação de 84 com o Minnesota Satisfaction Questionnaire - Short Form de Weiss, Dawis, England, \& Lofquist, 1967). A estrutura factorial é consistente com a da versão original. Discutem-se ainda algumas questões a ser exploradas em próximas investigações, tendo em conta as limitações inerentes a este estudo.

PALAVRAS-CHAVE: satisfação com o trabalho; Cuestionario de Satisfacción Laboral S2O/23; propriedades psicométricas; análise factorial

\section{Introdução}

A complexidade do mundo do trabalho acentua-se numa sociedade actual pautada por constantes e céleres transformações tecnológicas, políticas e ideológicas a

\footnotetext{
1 Faculdade de Psicologia e de Ciências da Educação da Universidade de Coimbra, Portugal - jferreira@ fpce.uc.pt

2 Escola Superior de Educação do Instituto Politécnico de Viseu, Portugal

3 Faculdade de Psicologia e de Ciências da Educação da Universidade de Coimbra, Portugal

4 IDOCAL da Universidade de Valência e IVIE, Espanha
} 
uma escala global. A elevada competitividade a que as organizações estão sujeitas tem vindo a alterar os seus tradicionais padrões de funcionamento.

Cada vez mais a sua preocupação se centra na melhoria da qualidade dos seus produtos, antecipando e superando as expectativas dos seus clientes externos (consumidores) de forma a promover a sua satisfação (Martínez-Tur, Peiró Ramos, 2001). Contudo, a satisfação dos seus clientes internos (trabalhadores) tem vindo também a mobilizar esforços por parte das organizações. Aliás, hoje os trabalhadores não são vistos como simples mão-de-obra, mas como colaboradores ou parceiros, tendo em conta que a sua satisfação pode afectar os processos organizacionais, a qualidade do produto e a produtividade esperada. (Hernandez \& Melo, 2003). Manter os trabalhadores satisfeitos no seu trabalho é um pré-requisito para uma organização eficaz e eficiente (Saane, Sluiter, Verbeek, \& Frings-Dresen, 2003)

A par destas questões economicistas, emerge a preocupação de carácter humanístico, tendo em conta que tem vindo a ser demonstrado pela investigação que trabalhadores insatisfeitos também apresentam níveis de satisfação baixos com outros aspectos da vida não relacionados com o trabalho (Levinson, 1998). Esta valorização crescente da promoção do bem-estar está bem patente na recente atenção dos investigadores no âmbito da psicologia positiva (Simões, Ferreira, Lima, Pinheiro, Vieira, Matos \& Oliveira, 2000; Peiró \& Tetrick 2011). Os investigadores reconhecem a importância da satisfação com o trabalho para os trabalhadores na sua procura de significado, propósito e satisfação em geral com a vida (Hagihara, Tarumi, Babazono, Nobutomo, \& Morimoto, 1998; Trott, 1996; cit in Robert, Young \& Kelly, 2006).

Robert, Young e Kelly (2006) salientam vários estudos recentes que têm evidenciado uma relação entre os baixos níveis de satisfação com o trabalho e uma variedade de problemas de saúde associados ao stress como a depressão, ansiedade e perturbações aditivas (por exemplo, Cropanzano \& Wright, 2001; National Academy on an Aging Society, 2000; Walsh \& Srsic, 1995).

Estes problemas para além de afectarem a qualidade de vida do ser humano, têm repercussões no funcionamento da organização (Saane et al. 2003) no que concerne à sua produtividade e manutenção dos trabalhadores (Cropanzano \& Wright, 2001, cit in Robert, Young \& Kelly, 2006).

Neste contexto, a satisfação laboral dos trabalhadores e os vários factores associados a esta dimensão (produtividade, desempenho, absentismo e abandono laboral, entre outros), têm vindo a ser investigados nos últimos anos no âmbito da Psicologia Organizacional (Jewell, Beavers, Kirby \& Flowers, 2001), constituindo-se mesmo como a variável mais estudada por estes investigadores (Spector, 1997). 
Esta centralidade do constructo deve-se à sua influência (empiricamente demonstrada) na vida das organizações, quer ao nível específico - no domínio do trabalhador - quer numa esfera global do funcionamento geral da própria organização (Hirschfeld, 2000).

A relevância do estudo da satisfação com o trabalho não é apenas actual. De acordo com Pocinho e Garcia (2008), a história do estudo da satisfação profissional remonta ao ano de $1912 \mathrm{com}$ as pesquisas de Taylor sobre a influência do ambiente de trabalho (nomeadamente a fadiga e o salário) no desempenho do trabalhador, sua satisfação e produtividade. Mais tarde Mayo e seus colaboradores (1930)salientam que para além do salário há outros factores (como a natureza do trabalho, adaptabilidade do trabalhador, relações sociais, entre outros) que exercem mais influência sobre a satisfação do trabalhador, destacando a importância da forma como o trabalhador pensa e avalia o seu trabalho. Também Hoppock (1935) no primeiro estudo intensivo publicado sobre o tema, evidencia novos factores associados à satisfação com trabalho, como a supervisão, condições de trabalho, desempenho e outros.

Nesta retrospectiva histórica, as teorias da motivação representam um contributo importante na humanização das condições do trabalho com repercussões ao nível da satisfação com o trabalho. Neste contexto, a teoria de Maslow (1943,) ocupa um papel central, ao debruçar-se sobre a importância da satisfação hierárquica das necessidades humanas. Com base nestes princípios, emerge em 1959, a teoria de Herzberg, Mausner e Snyderman que categoriza em duas dimensões os factores associados à satisfação com o trabalho: intrínsecos (motivação) - com influência directa na satisfação - e extrínsecos ("higiene") - que previnem a insatisfação. No entanto, estas teorias associadas à satisfação de necessidades foram sendo desvalorizadas no seio da investigação científica sobre o tema.

Um dos modelos mais aceites na literatura é o de Locke $(1976,1984$,$) que defende$ que a satisfação com o trabalho resulta da percepção que o trabalhador tem sobre se o seu trabalho atende aos seus valores laborais que por sua vez são congruentes com as suas necessidades. Este autor determina que os factores associados à satisfação com o trabalho estão relacionados com o seu conteúdo, as possibilidades de promoção, o reconhecimento, as condições e ambiente de trabalho, as relações com colegas e subordinados, as características da supervisão e direcção, e as políticas/competências da organização.

Para Peiró (1997) existem factores associados à satisfação com o trabalho relativamente estáveis e consistentes: satisfação intrínseca, satisfação com a supervisão ou estilo de direcção, satisfação com a organização e direcção da mesma, satisfação com as condições de trabalho (fisicas e psicológicas), satisfação com as recompensas e orientações, e a satisfação com o reconhecimento através de feedback verbal. 
Mais recentemente, a satisfação com o trabalho é conceptualizada na perspectiva de Tamayo (2000, cit in Carlotto \& Câmara, 2008), também como uma variável multifatorial, incluindo aspectos como: salário, colegas, supervisão, oportunidades para promoção, benefícios, condições de trabalho, progressão na carreira, estabilidade no trabalho, desenvolvimento pessoal e quantidade de trabalho.

Existem várias perspectivas teóricas que procuraram explorar este constructo. Inicialmente a atenção centrava-se nos efeitos desta variável sobre outras, como o rendimento, absentismo e abandono laboral (Algag \& Brief, 1978, cit in Meliá, Pradilla, Martí, Sancerni, Oliver \& Tomás, 1990). Mais tarde a sua relevância para a qualidade laboral transformou-a numa variável com interesse em si mesma para a intervenção organizacional (Quinn \& Gonzales, 1979, cit in Meliá et al. 1990).

\section{Da definição à avaliação da satisfação com o trabalho}

Ainda que o conceito de satisfação profissional seja abordado no âmbito da Psicologia Social e Organizacional há várias décadas, como variável com interesse próprio, existe alguma controvérsia sobre a sua definição (Pedro \& Peixoto, 2006). Esta controvérsia resulta da complexidade do conceito, que pode variar entre os trabalhadores em diferentes circunstâncias e ao longo do tempo para o mesmo trabalhador (Carlotto \& Câmara, 2008). Devido à sua complexidade tem sido definida de várias formas dependendo do referencial teórico subjacente.

Segundo Peiró, Luque, Meliá e LosCertales (1991, as pessoas costumam ter uma ideia mais ou menos definida sobre como deveria ser o seu trabalho, esta avaliação é comparada com a realidade e daqui resulta um maior ou menor nível de satisfação. No mesmo sentido Dawis e Lofquist (1984, cit in Robert, Young \& Kelly, 2006) defendem que a satisfação global com o trabalho tem sido definida como uma atitude global positiva das pessoas em relação ao trabalho, com base na sua correspondência em relação às necessidades, valores e expectativas do trabalhador. Mais recentemente encontramos a concepção de Péres (2001), que define satisfação laboral como a atitude do trabalhador face ao seu próprio trabalho, resultante da interacção entre as características actuais do cargo desempenhado e as percepções que o trabalhador tem do que deveriam ser.

Parece-nos contudo existir algum consenso no âmbito da sua definição apesar da diversidade de modelos teóricos sobre este conceito. Assim, de acordo com Pedro e Peixoto (2006) geralmente é definida como um conjunto de sentimentos positivos ou negativos que o indivíduo manifesta em relação ao seu trabalho (Smith, Kendall \& Hulin, 1969, cit in Seco, 2000) resultante da comparação entre o que é esperado de uma situação e o que se conseguiu obter dela (Locke, 1976, cit in 
Heitor, 1996), salientando o importante papel que a concretização das expectativas assume na satisfação no trabalho (Cabral, Vala \& Freire, 2000).

Apesar das várias conceptualizações teóricas encontradas na literatura sobre os factores do trabalho (mais ou menos específicos) relevantes para a satisfação com o mesmo, raramente encontramos referência aos aspectos do trabalho que devem ser tidos em conta quando se avalia a satisfação com o trabalho (Saane et al. 2003). De facto, algumas das variáveis teoricamente associadas à satisfação com o trabalho não estão incluídas nos instrumentos e podem influenciar os resultados. Contudo, seria extremamente difícil controlar todas características que podem afectar a satisfação profissional. Por isso, quando se avalia esta dimensão, é necessário ter em consideração que podem existir muitas outras variáveis para além daquelas que são avaliadas com os instrumentos (Ahmadi \& Alireza, 2007).

Neste sentido, Sutton e Staw (1995) referem que os problemas associados à avaliação da satisfação com o trabalho persistem, carecendo de padrões metodológicos no campo da investigação. Carlotto e Câmara (2008) acrescentam que Staw (1984) e Bussing, Bissels, Fuchs e Perrar (1999) apontam outro problema na avaliação da satisfação com o trabalho, que se relaciona com a utilização de instrumentos sem modelos teóricos que os sustentem. A este propósito, Martins e Santos (2006), referem que os instrumentos possuem bases conceptuais diversas portanto quando são utilizados, muitas vezes não se sabe o que está a ser avaliado.

Independentemente destes problemas associados à avaliação da satisfação com o trabalho, a sua relevância é evidente quer ao nível da investigação quer da intervenção organizacional. Esta importância é bem visivel, se tivermos em conta a quantidade e variedade de instrumentos de avaliação construídos ao longo dos tempos para estes efeitos.

Cook et al. (1981) classificaram os vários instrumentos de avaliação organizandoos de acordo com os conteúdos dos itens. Assim, há instrumentos cujos itens avaliam diferentes aspectos do trabalho (obtendo-se um nível de satisfação geral através da soma das pontuações ao longo da escala); outros que se centram em questões mais gerais, como por exemplo, "quão satisfeito está com o seu actual trabalho?"; e ainda instrumentos que incluem aspectos específicos e gerais da satisfação com o trabalho (Meliá et al. 1990).

Um dos instrumentos mais utilizados na avaliação da satisfação com o trabalho e que permite obter simultaneamente um resultado global e também resultados para duas dimensões de satisfação (intrínseca e extrínseca) é o Minnesota Satisfaction Questionnaire - Short Form (Weiss, Dawis, England \& Lofquist, 1967). Outro instrumento deste tipo é o Cuestionario de Satisfacción Laboral S4/82 desenvolvido por Meliá, Peiró e Calatayud (1986). 


\section{Cuestionario de Satisfaccion S20/23 (Meliá \& Peiró, 1989a)}

Neste contexto de heterogeneidade instrumental surgiu o Cuestionario General de Satisfacción en Organizaciones Laborales S4/82 desenvolvido por Meliá, Peiró e Calatayud (1986) com o objectivo de permitir uma minuciosa e específica avaliação da satisfação com o trabalho (envolvendo um conteúdo amplo de factores associados a esta variável) tendo em conta as especificidades culturais e organizacionais espanholas (Meliá et al. 1990).

De acordo com Meliá et al. (1990) o questionário S4/82 inclui diferentes aspectos da satisfação com o trabalho que se adequam a diferentes organizações e ocupações profissionais, quer para fins de investigação quer para objectivos de consultadoria. Estes aspectos correspondem a 6 factores: (1) satisfação com a supervisão e participação na organização; (2) satisfação com o ambiente físico de trabalho; (3) satisfação com os benefícios materiais e outras recompensas complementares; (4) satisfação intrínseca com o trabalho; (5) satisfação com o salário, benefícios básicos e segurança no emprego; e (6) satisfação com as relações interpessoais (Meliá et al. 1990).

Apesar de apresentar qualidades psicométricas muito satisfatórias (consistência interna de .95 e validade demonstrada empiricamente em vários estudos), a sua aplicação implica custos elevados, pois é um instrumento bastante extenso ( 82 itens). Para além disso, as alternativas de resposta inscrevem-se numa escala de resposta constituída por 7 pontos (muito insatisfeito, bastante insatisfeito, algo insatisfeito, indiferente, algo satisfeito, bastante satisfeito e muito satisfeito) e o que se tem verificado, é que devido à exaustividade do conteúdo, surgem muitas respostas na categoria 4 (indiferente), talvez porque inclui aspectos muito específicos que por vezes não se relacionam com o contexto laboral do trabalhador (Meliá et al. 1990).

Com base nestes dados, os autores desenvolveram versões mais reduzidas do instrumento $\left(S_{20} / 23, S_{10} / 12\right.$ e $\left.S_{21 / 26}\right)$, evitando itens característicos de determinadas ocupações profissionais, mas procurando manter as suas propriedades psicométricas (Meliá et al. 1990).

A versão reduzida S20/23 (Meliá \& Peiró, 1987) inclui 23 itens extraídos do questionário original, mediante um processo de análise e selecção de itens orientado por concepções teóricas e resultados empíricos, procurando incluir aqueles que: (1) apresentem conteúdo relevante; (2) maximizem a validade de critério; (3) sustentem a fidelidade do instrumento; e (4) mantenham a consistência e coerência da estrutura factorial da versão completa (Silva, 2003). Deste processo resultou a versão com estrutura factorial de 5 factores: (1) satisfação com a supervisão; (2) satisfação com o ambiente físico; (3) satisfação com os benefícios recebidos; (4) satisfação intrínseca com o trabalho; e (5) satisfação com a participação (Meliá \& Peiró, 1989a). 
Uma versão ainda mais reduzida (mais rápida e menos dispendiosa) é o S10/12 (Meliá \& Peiró, 1988), que inclui apenas 12 itens retirados do S2O/23 e desta feita, estruturado em 3 dimensões: (1) satisfação com a supervisão; (2) satisfação com o a mbiente físico; e (3) satisfação com os benefícios recebidos (Meliá et al. 1990).

Estas duas versões mantêm as alternativas de resposta numa escala de Likert de 7 pontos. Apesar destas versões reduzidas se revelarem menos dispendiosas que a versão original, ainda assim o seu formato de resposta implica custos temporais e algumas dificuldades de resposta especialmente relacionadas com a idade e o nível profissional/educativo dos trabalhadores, que em situações de intervenção podem não ser ajustadas. Assim surgiu mais uma versão reduzida do instrumento, o S21/26 constituído por 26 itens, mas com resposta em formato dicotómico (evitando as respostas centradas na categoria 4) mantendo as qualidades psicométricas da versão original e apresentando uma estrutura factorial constituída por 6 factores: (1) satisfação com a supervisão e participação; (2) satisfação com o salário e benefícios; (3) satisfação intrínseca com o trabalho; (4) satisfação com o ambiente físico; (5) satisfação com a quantidade de produção; e (6) satisfação com a qualidade da produção (Meliá et al. 1990).

A versão original $\left(\mathrm{S}_{4} / 82\right)$ permite obter um índice global de satisfação laboral e índices específicos para diversas facetas da satisfação (Meliá \& Peiró, 1989b), constituindo-se um instrumento útil para diagnósticos pormenorizados em intervenção organizacional. Contudo, a versão S20/23 pode considerar-se a versão reduzida mais completa estruturalmente (correlacionando-se em .92 com a versão original, de acordo com Meliá et al. 1990), permitindo igualmente uma avaliação útil e rica de conteúdo, atendendo às limitações motivacionais e temporais a que estão sujeitos os trabalhadores em contextos organizacionais (Meliá \& Peiró, 1989a). É instrumento de fácil compreensão e aplicação, demorando apenas cerca de 10 minutos a ser preenchido (Carlotto \& Câmara, 2008)

As instruções são mais breves que as da versão original: "Normalmente o trabalho e os diferentes aspectos do mesmo, produzem satisfação ou insatisfação em algum grau. Classifique de acordo com as seguintes alternativas o grau de satisfação ou insatisfação que produzem os aspectos distintos do seu trabalho." (Meliá \& Peiró, 1989a).

As alternativas de resposta, mantém a escala de Likert de 7 pontos da versão original (variando a pontuação total entre 23 e 161): (1) muito insatisfeito, (2) bastante insatisfeito, (3) algo insatisfeito, (4) indiferente, (5) algo satisfeito, (6) bastante satisfeito e (7) muito satisfeito (Meliá \& Peiró, 1989a). As respostas no processo de construção do S20/23 oscilaram entre a categoria 3 e a 6 , tendo surgido os resultados mais baixos nos itens relativos à formação, progressão e negociação e os mais altos nos aspectos intrínsecos do trabalho e ambiente físico (Meliá \& Peiró, 1989a). 
A distribuição dos 23 itens pelos 5 factores que constituem o questionário encontra-se descrita no Quadro 1. Meliá e Peiró (1989a) encontraram correlações positivas entre todos os itens o que indica uma forte relação entre os diversos conteúdos incluídos no instrumento. A este dado acresce-se o valor elevado de consistência interna para a escala total (.92) e para os diferentes factores (.89, $.81, .76, .80$ e .78 , o que tendo em conta o reduzido número de itens constituem excelentes resultados).

Quadro 1. Itens do $\mathrm{S}_{20} \mathrm{O} / 23$ organizados por factores

\begin{tabular}{|c|c|}
\hline Itens & Factores \\
\hline $\begin{array}{l}\text { 13. As relações pessoais com os seus superiores hierárquicos. } \\
\text { 14. A supervisão recebida. } \\
\text { 15. A proximidade e a frequência com que é supervisado.supervi- } \\
\text { sionado. } \\
\text { 16. A forma como os seus superiores avaliam as suas tarefas. } \\
\text { 17. A "igualdade" e a "justiça" no tratamento que recebe da sua } \\
\text { instituição/empresa.de su empresa. } \\
\text { 18. O apoio que recebe dos seus superiores hierárquicos. }\end{array}$ & $\begin{array}{l}\text { I } \\
\text { Satisfação } \\
\text { com a Supervisão } \\
\text { (6 itens) }\end{array}$ \\
\hline $\begin{array}{l}\text { 6. A limpeza, higiene e saúde do seu local detrabajo. trabalho. } \\
\text { 7. O ambiente físico e o espaço de que dispõe nosu lugar de tra- } \\
\text { bajo. seu local de trabalho. } \\
\text { 8. A iluminação do seu local de trabalho. } \\
\text { 9. La ventilación de su lugar de trabajo.A ventilação do seu local de } \\
\text { trabalho. } \\
\text { 10. A temperatura do seu local de trabalho. }\end{array}$ & $\begin{array}{l}\text { II } \\
\text { Satisfação com o } \\
\text { Ambiente Físico } \\
\text { (5 itens) }\end{array}$ \\
\hline $\begin{array}{l}\text { 4. O salário que recebe. } \\
\text { 11. As oportunidades de formação oferecidas pela instituição/em- } \\
\text { presa.empresa. } \\
\text { 12. As oportunidades de progressão profissional. } \\
\text { 22. O grau em que a sua instituição/empresa cumpre a legislação } \\
\text { laboral. } \\
\text { 23. A forma como se realiza a negociação relativa a aspectos labo- } \\
\text { rais na sua instituição/empresa. }\end{array}$ & $\begin{array}{l}\text { III } \\
\text { Satisfação } \\
\text { com os Benefícios } \\
\text { (5 itens) }\end{array}$ \\
\hline $\begin{array}{l}\text { 1. A satisfação que o trabalho produz por si mesmo. } \\
\text { 2. As oportunidades oferecidas pelo seu trabalho para realizar } \\
\text { tarefas em que se destaca. } \\
\text { 3. As oportunidades oferecidas pelo seu trabalho para realizar tare- } \\
\text { fas que gosta } \\
\text { 5. Os objectivos, metas e índices de produção que deve alcançar. } \\
\text { debe alcanzar. }\end{array}$ & $\begin{array}{l}\text { IV } \\
\text { Satisfação In- } \\
\text { trínseca } \\
\text { (4 itens) }\end{array}$ \\
\hline $\begin{array}{l}\text { 19. A capacidade de decidir autonomamente aspectos relativos a } \\
\text { su trabajo.aspectos relativos ao seu trabalho. } \\
\text { 20. A sua participação nas decisões do seudepartamento o sección. } \\
\text { Departamento ou secção. } \\
\text { 21. La capacidad para decidir autónomamenteSu participación en } \\
\text { las decisiones de suSu participación en las decisiones de su grupoA } \\
\text { sua participação nas decisões do seu grupo de trabalho relativas à } \\
\text { instituição/empresa. }\end{array}$ & $\begin{array}{l}\text { V } \\
\text { Satisfação } \\
\text { com a Participação } \\
\text { (3 itens) }\end{array}$ \\
\hline
\end{tabular}


Os autores verificaram ainda ao nível da validade, na sua relação com a versão original, que o S20/23 explica 84.64 \% da variância (relembra-se que a versão completa é 3.56 vezes maior). Salientando-se apenas a não representação do factor 6 na versão reduzida por não ter apresentado no processo de redução do instrumento original relação suficientemente forte com os critérios externos utilizados - relações negativas com abandono laboral, tensão, conflito e ambiguidade de papéis (Meliá \& Peiró, 1989a).

De igual modo, no estudo de Carlotto e Câmara (2008) de adaptação do instrumento à população brasileira, a escala total apresentou um valor de consistência interna elevado (.91), todas as dimensões apresentaram consistência interna satisfatória (acima de .77) e validade de constructo adequada. No entanto, os resultados revelaram uma nova estrutura factorial, no que diz respeito ao número de items e definição das dimensões: (1) satisfação com relações hierárquicas (incluindo todos os itens do factor I e V e os itens 22 e 23 do factor III); (2) satisfação com o ambiente físico de trabalho (igual ao factor II); (3) satisfação intrínseca no trabalho (itens do factor IV e os itens 4, 11 e 12 do factor III, que saturaram em mais de um factor, pelo que foram excluídos da versão brasileira do instrumento). Esta estrutura é coerente e apoiada pelo modelo teórico da satisfação com o trabalho de Locke (1984) adoptado pelos autores na escala original (Carlotto \& Câmara, 2008).

Num estudo realizado em contexto nacional por Pocinho e Garcia (2008) de adaptação do instrumento à população portuguesa, o S2O/23 apresentou mais uma vez qualidades psicométricas adequadas embora inferiores à versão espanhola (consistência interna de .80 para a escala total, um mínimo de .70 para os diferentes factores e estrutura factorial adequada), revelando os requisitos necessários para ser utilizada na população portuguesa.

A presente investigação constitui-se assim como um contributo adicional para o estudo das propriedades métricas do Cuestionario de Satisfaccion S20/23 (Meliá \& Peiró, 1989a) em contexto português, nomeadamente no que concerne à sua fidelidade (através da análise da consistência interna e da estabilidade teste-reteste) e validade convergente (pela correlação dos seus resultados com os obtidos através do Minnesota Satisfaction Questionnaire - Short Form de Weiss et al. 1967). Procurou-se ainda através da análise factorial exploratória compreender a estrutura factorial do instrumento. 


\section{Metodologia}

\subsection{Participantes}

Participaram neste estudo 93 trabalhadoras e 42 trabalhadores (constituindo uma amostra total de 136 participantes, salientando-se que um dos participantes não assinalou a sua resposta nesta questão), variando a faixa etária entre $21 \mathrm{e}$ 60 anos ( $M=36.60, D P=9.72)$. Quanto ao estado civil, verificou-se que $45.6 \%$ são casados e $38.2 \%$ são solteiros, constituindo estes dois estados a maioria da amostra. Relativamente ao número de filhos, verificou-se que a média é inferior a 1 , variando entre o e 3 , seguindo o que tendencialmente tem vindo a constatarse no nosso país.

A fim de garantir uma amostra heterogénea, incluíram-se participantes de diferentes regiões de Portugal e diversos sectores de actividade profissional (incluindo 53 professores, 23 profissionais da área da economia e comércio, 12 da área das ciências sociais e humanas, bem como, diversos profissionais de outras áreas desde a indústria, artes, saúde, engenharia e tecnologias, militar, estética, direito, entre outras). Por conseguinte, verificou-se alguma variedade quanto à área de formação: ciências sociais e humanas, educação/ensino, economia, ciências, engenharia/tecnologias, artes, comunicação, desporto, línguas, serviço militar, saúde, direito e turismo. Em média, o tempo de permanência no emprego actual foi de aproximadamente 11 anos (variando entre 1 e 37 anos).

Verificou-se ainda alguma correspondência relativamente à ocupação do cônjuge, sendo a maioria professores, profissionais da área da economia, e ainda profissionais da área da engenharia/tecnologias.

Procurou-se também incluir alguma diversidade quanto ao nível educacional, contudo, os participantes com formação ao nível do ensino superior aderiram em maior número ao estudo (94) trabalhadores. No entanto, participaram também 27 adultos com habilitações literárias ao nível do ensino secundário e 13 do ensino básico.

É de referir que no estudo de fidelidade, através da análise dos coeficientes de correlação teste-reteste, foi utilizada uma sub-amostra de 26 participantes.

\subsection{Instrumentos}

A fim de caracterizar os participantes na sua dimensão sócio-demográfica e profissional foi aplicado um Questionário de Caracterização Geral. Na primeira dimensão foram incluídas questões relacionadas com a idade, sexo, localidade, estado civil, número de filhos, habilitações académicas, área de formação, pro- 
fissão e ocupação do cônjuge. Relativamente à sua situação profissional actual, incluíram-se três questões: estabilidade (há quanto tempo desempenha actual profissão), satisfação actual com o trabalho em geral (avaliada numa escala de 4 pontos - muito insatisfeito, insatisfeito, satisfeito e muito satisfeito) e sucesso profissional actual também numa escala de 4 pontos - muito sucesso, algum sucesso, pouco sucesso, nenhum sucesso).

Os participantes preencheram ainda dois instrumentos de avaliação da satisfação com o trabalho, o Cuestionario de Satisfaccion Laboral S2O/23 de Meliá e Peiró (1989a) e o Minnesota Satisfaction Questionnaire - Short Form (Weiss et al. 1967), a fim de se analisar a consistência interna do primeiro e a sua validade convergente, correlacionando os seus resultados com os obtidos no segundo instrumento.

Relembra-se que o Cuestionario de SatisfaccionLaboral S20/23 de Meliá e Peiró (1989a), descrito anteriormente, resulta da revisão do Cuestionario de Satisfacción Laboral S4/82 mediante um processo de análise e selecção de 23 itens baseados em orientações teóricas e evidência empírica (Meliá et al. 1990). Estes itens são cotados numa escala de 7 pontos (1- muito insatisfeito, 2 - bastante insatisfeito, 3 - algo insatisfeito, 4 -indiferente, 5 - algo satisfeito, 6 - bastante satisfeito e 7 - muito satisfeito) e organizam-se em 5 factores: (1) satisfação com supervisão; (2) satisfação com ambiente físico de trabalho; (3) satisfação com benefícios e políticas da organização; (4) satisfação intrínseca com o trabalho; e (5) satisfação com a participação (Carlotto \& Câmara, 2008). A cotação total do instrumento varia entre 23 e 161. De acordo com os autores apresenta um coeficiente alfa de Cronbach de .92 e há evidência empírica quanto à sua validade de constructo, demonstrada por exemplo, no estudo de Carlotto e Câmara (2008).

O Minnesota Satisfaction Questionnaire (MSO) - Short Form (Weiss et al. 1967), foi igualmente administrado aos participantes, tendo revelado características psicométricas adequadas em estudos realizados em diferentes países, nomeadamente em Portugal (Ferreira, Fernandes, Haase, \& Santos, 2009). De acordo com os autores apresenta um coeficiente de consistência interna de .87 (variando para os itens entre .74 e .91) e revela validade divergente para as duas componentes da satisfação com o trabalho (intrínseca e extrínseca) nas suas relações com outras variáveis relevantes (Brown, 1996; Moorman, 1993; Bouchard, 1997). Este instrumento é também uma versão reduzida do instrumento original, incluindo 20 itens organizados em duas subescalas (satisfação intrínseca e extrínseca). Cada item é respondido pelo trabalhador numa escala de 5 pontos: muito insatisfeito (cotação 1), insatisfeito (cotação 2), indeciso (cotação 3), satisfeito (cotação 4) e muito satisfeito (cotação 5). Assim, a cotação global do instrumento pode variar entre 20 e 100 (entre 12 e 60 para a subescala de satisfação intrínseca e entre 6 e 30 para a subescala de satisfação extrínseca). 
O tempo total necessário para o preenchimento dos três instrumentos foi de aproximadamente 15 minutos.

\subsection{Procedimento}

Após ter sido pedida permissão (autorizada) a Meliá e Peiró, bem como, à University of Minnesota - Vocational Psychology Research para se utilizar os instrumentos em contexto português, procedeu-se à tradução e retroversão dos mesmos (apesar do Cuestionario de Satisfaccion S20/23 de Meliá e Peiró, 1989a já ter sido utilizado na população portuguesa por Pocinho e García em 2008). Os instrumentos traduzidos foram aplicados a um pequeno grupo de participantes. Através da reflexão falada, surgiu a necessidade de efectuar alguns ajustes ao nivel da linguagem, não se verificando no entanto, problemas ao nível da compreensibilidade dos itens.

O passo seguinte consistiu em contactar os participantes (cumprindo o critério de estar a exercer a sua profissão há pelo menos um ano) pessoalmente (6o participantes) ou via electrónica (76 participantes preencheram os instrumentos disponíveis online), informando-os sobre o objectivo do estudo e garantindo a confidencialidade e anonimato no tratamento dos dados. Não se verificaram diferenças significativas entre os dois formatos de recolha de dados, o que sugere que a utilização da internet não afecta os resultados (tal como no estudo realizado por Field, Holley e Armenakis em 1978 no âmbito da satisfação com o trabalho).

No intervalo temporal de aproximadamente um mês, os mesmos instrumentos foram aplicados a 26 participantes da amostra total. A recolha de dados decorreu no ano de 2009 .

\subsection{Resultados}

Os dados foram analisados quantitativamente recorrendo ao Statistical Package for the Social Sciences - SPSS (versão 17.0) envolvendo duas etapas. A primeira centrada em análises gerais sobre a satisfação profissional (estatísticas de carácter descritivo, comparação entre grupos e análise da relação entre variáveis) e a segunda procurando responder às questões levantadas neste estudo sobre as propriedades psicométricas do $520 / 23$.

Efectuaram-se ainda análises prévias de forma a determinar a normalidade da distribuição e verificar a existência de outliers susceptíveis de influenciar significativamente os resultados. Constatou-se, tal como é esperado em grandes amostras de estudos realizados na área das ciências sociais, nomeadamente quando se 
avaliam constructos como a satisfação (Pallant, 2001), que a assimetria e curtose dos resultados dos dois instrumentos de avaliação da satisfação profissional, se afastam do valor zero, reflectindo a natureza do constructo subjacente. Também o recurso ao teste de Kolmogorov-Smirnov revelou não estarem cumpridos os pressupostos da normalidade $(p<.05)$ ao nível da distribuição dos resultados de satisfação profissional. Contudo, não foram identificados casos de outliers que possam afectar a adequada análise dos dados.

\subsubsection{Análises gerais da satisfação com o trabalho}

Depois de verificados estes pressupostos, procedeu-se à análise descritiva dos resultados. No que diz respeito às questões incluídas no questionário de caracterização sócio-demográfica, relativas à satisfação geral com o trabalho e sucesso profissional actual (avaliadas numa escala de quatro pontos), constatou-se que os participantes se encontram relativamente satisfeitos com a sua situação laboral $(M=2.90, D P=.82)$, referindo que actualmente têm algum sucesso profissional $(M=3.13, D P=.54)$.

Relativamente aos resultados de satisfação com o trabalho, avaliados pelo $\mathrm{S} 2 \mathrm{O} / 23$ foi possivel constatar que em média os participantes também se encontram moderadamente satisfeitos com o trabalho apresentando uma média de 110.07 (DP $=26.16)$ num total possível de 161, como pode ser verificado no Quadro 2.

Quadro 2. Notas médias, desvios-padrão, mínimos e máximos no S20/23 e respectivos factores

\begin{tabular}{l|c|c|c|c|c}
\hline & $\mathrm{N}$ & $\mathrm{M}$ & $\mathrm{DP}$ & Min. & Max. \\
\hline Factor I - Supervisão & 131 & 28.01 & 8.48 & 6 & 42 \\
\hline Factor II - Ambiente Físico & 136 & 24.76 & 7.72 & 5 & 35 \\
\hline Factor III - Benefícios & 132 & 21.14 & 7.26 & 5 & 33 \\
\hline Factor IV - Intrínseca & 133 & 20.74 & 4.24 & 9 & 28 \\
\hline Factor V - Participação & 135 & 15.55 & 4.06 & 4 & 21 \\
\hline S20/23 Total & 128 & 110.07 & 26.16 & 47 & 156 \\
\hline
\end{tabular}

Constatou-se que os participantes se manifestam mais satisfeitos (tendo em conta os valores máximos possíveis para cada factor) com a dimensão intrínseca da satisfação profissional, depois ao nível da participação, ambiente físico, supervisão e por último, no que concerne aos benefícios.

Ao nivel dos itens, verificou-se que apenas o primeiro (satisfação com o trabalho em si mesmo) não teve respostas com cotação 1 (muito insatisfeito), que foi precisamente o que apresentou média mais elevada $(M=5.54$, DP $=1.00)$. Por sua vez, o item que revelou um nível médio de satisfação mais baixo nesta amostra foi o 11 - oportunidades de formação $(M=3.96$, $D P=1.83)$. 
Relativamente aos resultados do MSQ - versão reduzida, a nota média foi 74.31 $(\mathrm{DP}=13.78)$ num total possivel de 100, o que revela igualmente uma satisfação moderada com o trabalho. Mais uma vez, os participantes revelaram-se mais satisfeitos com os aspectos da dimensão intrínseca em comparação com os factores extrínsecos associados à satisfação com o trabalho.

A análise comparativa entre grupos com base na faixa etária (utilizado o procedimento One-Way ANOVA), permitiu constatar algumas diferenças estatisticamente significativas ao nível da satisfação profissional avaliada com o \$20/23 (depois de verificado que não era violado o pressuposto de homogeneidade das variâncias, através do teste de Levene).

Assim, nos itens 7 - ambiente físico e espaço $[F(2,133)=5.42, p=.005], 8-$ iluminação $[F(2,133)=6.20, p=.003]$ e 9 - ventilação $[F(2,133)=7.23, p=.001]$ e no Factor II - Ambiente Físico $[F(2,133)=5.69, p=.004]$ constatam-se diferenças significativas entre os participantes de diferentes faixas etárias.

Procurou-se perceber o sentido destas diferenças recorrendo-se ao teste de Turkey que revelou que estas diferenças eram significativas ( $p<.05)$ entre os grupos de participantes, excepto entre os trabalhadores com mais de 50 anos e os com idades compreendidas entre 31 e 49 anos. Calculou-se ainda o tamanho do efeito para a população ( $d$ de Cohen), tendo-se verificado que este era médio para o item 7 $\left(\right.$ eta $\left.^{2}=.09\right)$ e elevado para os itens 8 (eta $\left.{ }^{2}=.14\right), 9\left(\right.$ eta $\left.^{2}=.12\right)$ e Factor II (eta $\left.{ }^{2}=.22\right)$.

Tendo em conta os resultados mais baixos nestas condições estruturais do local de trabalho apresentados pelos participantes mais novos (menos de 30 anos), os dados sugerem que os participantes mais novos estão menos satisfeitos com estas condições do que os restantes participantes.

Aliás esta variável relativa à faixa da etária dos participantes, para além de se correlacionar positiva e moderadamente com os itens $7(r=.27, p=.002), 8(r=$ $.29, p=.001)$ e $9(r=.31, p<.001)$ e o Factor II $(r=.28, p=.001)$, ainda apresentou correlações positivas embora fracas com os itens 1 - trabalho em si mesmo $(r=$ .19, $p=.03), 6$ - limpeza, higiene e saúde $(r=.17, p=.04)$ e 10 - temperatura $(r$ $=.19, p=.02$ ).

Também as habilitações literárias dos participantes se correlacionaram positivamente com os resultados de satisfação profissional, embora com valores de $r$ inferiores a .29, sugerindo uma relação fraca entre as variáveis. Assim, os participantes com mais habilitações literárias revelam-se mais satisfeitos com: (1) a igualdade e justiça no tratamento que recebem ( $r=.19, p=.03$ ); (2) a possibilidade de tomar decisões de forma autónoma $(r=.18, p=.04)$; (3) a sua participação nas decisões do departamento/secção $(r=.20, p=.02)$; e também (4) nas decisões do 
grupo de trabalho $(r=.21, p=.02)$. Duma forma geral, parecem mais satisfeitos com a sua participação na organização - Factor $V(r=.21, p=.01)$.

Outras variáveis exploradas no Questionário de Caracterização Geral que revelaram associações com os resultados do $\mathrm{S}_{20} / 23$, foram as questões de avaliação da satisfação geral com o trabalho e sucesso profissional actual, que por sua vez se correlacionaram positiva e moderadamente entre si $(r=.30, p<.001)$. Estas duas questões correlacionaram-se positivamente com todos os itens do S2O/23 (umas vezes fraca, outras moderadamente).

Também ao nível dos factores se verificaram correlações positivas fracas a moderadas com estas duas questões. Salientam-se como mais elevadas a correlação entre a satisfação geral e o Factor IV - satisfação intrínseca $(r=.43, p<.001)$ e entre o sucesso actual e o mesmo factor $(r=.49, p<.001)$.

Mais uma vez estas duas questões, relativas à satisfação geral e sucesso actual, correlacionam-se positiva e moderadamente com o resultado total do S2O/23 (r $=.43, \mathrm{p}<.001$ e $\mathrm{r}=.38, \mathrm{p}<.001$, respectivamente).

\subsubsection{Análise das propriedades psicométricas do $S_{20} / 23$}

A exploração da fidelidade do instrumento realizou-se através do cálculo da consistência interna (alfa de Cronbach) para a escala total e para os cinco factores que a constituem. Estes resultados podem ser visualizados no Quadro 3.

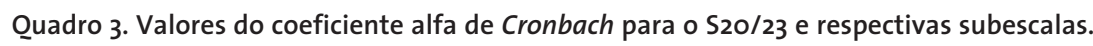

\begin{tabular}{l|c|c}
\hline & Alfa de Cronbach & Número de Itens \\
\hline S20/23 Total & .95 & 23 \\
\hline Factor I-Supervisão & .94 & 6 \\
\hline Factor II - Ambiente Físico & .93 & 5 \\
\hline Factor III - Benefícios & .85 & 5 \\
\hline Factor IV - Intrínseca & .84 & 4 \\
\hline Factor V - Participação & .90 & 3 \\
\hline
\end{tabular}

Como se pode verificar no Quadro 3, o instrumento em análise apresentou valores bastantes elevados de consistência interna quer para a escala total (.95), quer para os cinco factores subjacentes (entre .84 e .94).

Estes valores do coeficiente alfa de Cronbach no que diz respeito aos factores, destacam-se como bastante positivos tendo em conta o reduzido número de itens que os constituem, já que nenhum apresentou resultados abaixo do que é desejável (.70) como recomendado por Nunnally (1978, cit in Pallant, 2001) para 
subescalas com menos de 10 itens. O Factor IV (Intrínseca) apresenta o resultado mais baixo (.84), enquanto o Factor I - Supervisão revela o valor mais elevado (.94), no que concerne aos factores que constituem o S2O/23.

Constatou-se ainda que nenhum dos itens dos cinco factores aumentava o valor de alfa da respectiva subescala se retirado.

Estes dados são reforçados pelos elevados valores das intercorrelações entre factores, e entre estes e a nota total, após o cálculo dos respectivos coeficientes de correlação de Pearson indicados no Quadro 4.

Quadro 4. Intercorrelações entre factores e nota global no $\$ 20 / 23$

\begin{tabular}{l|c|c|c|c|c|c}
\hline & $\mathrm{S} 2 \mathrm{O} / 23$ & $\mathrm{I}$ & $\mathrm{II}$ & $\mathrm{III}$ & $\mathrm{IV}$ & $\mathrm{V}$ \\
\hline Factor I-Supervisão & .84 & & & & & \\
\hline Factor II - Ambiente Físico & .77 & .44 & & & & \\
\hline Factor III - Benefícios & .89 & .68 & .61 & & & \\
\hline Factor IV - Intrínseca & .84 & .66 & .56 & .71 & & \\
\hline Factor V - Participação & .82 & .68 & .54 & .67 & .68 & \\
\hline
\end{tabular}

Pela análise do Quadro 4, é possível constatar que todas as correlações são fortes, salientando-se as que ocorrem entre os factores e a nota total do S2O/23. A mais elevada surge entre a nota total e o Factor III - Benefícios (.89).

Também ao nível dos itens se verificaram fortes correlações com a nota total, salientando-se o item 13 (relações pessoais com supervisores) com o valor mais alto (.80). Por sua vez, o item 1 (trabalho em si mesmo) apresenta o valor mais baixo de correlação com o resultado total do S2O/23 (.59) mas ainda assim muito elevado.

Ainda no âmbito do estudo da fidelidade do instrumento, a análise das correlações entre os resultados da a plicação dos instrumentos num primeiro momento (t1) e num segundo momento ( $\mathrm{t} 2$ ), vem confirmar as adequadas qualidades psicométricas do instrumento, como se pode verificar no Quadro 5.

Quadro 5. Coeficientes de estabilidade para o $\mathrm{S}_{20 / 23}$

\begin{tabular}{|c|c|c|c|c|c|c|}
\hline & $\mathrm{S}_{2} \mathrm{O} / 23\left(\mathrm{t}_{1}\right)$ & $\mathrm{I}(\mathrm{t} 1)$ & II (t1) & III (t1) & IV (t1) & $\mathrm{V}(\mathrm{t} 1)$ \\
\hline S2O/23 Total (t2) & $.89^{* \prime}$ & $.64^{* *}$ & $.82^{* *}$ & $.77^{*}$ & $.75^{* \prime}$ & $.71^{* *}$ \\
\hline Factor I - Supervisão (t2) & $.86^{* *}$ & $.85^{* \prime}$ & $.54^{* *}$ & $.72^{* *}$ & $.68^{* *}$ & $.73^{* *}$ \\
\hline Factor II - Ambiente Físico (t2) & $64^{* *}$ & .26 & $.91^{* *}$ & $.55^{* *}$ & $.50^{*}$ & $.42^{*}$ \\
\hline Factor III - Benefícios (t2) & $.88^{* *}$ & $.66^{* *}$ & $.70^{* *}$ & $.85^{* *}$ & $.68^{* *}$ & $.75^{* *}$ \\
\hline Factor IV - Intrínseca (t2) & $.72^{* *}$ & $.45^{*}$ & $.67^{* *}$ & $.58^{* *}$ & $.83^{* *}$ & $.48^{*}$ \\
\hline Factor V - Participação (t2) & $.60^{*}$ & .35 & $64^{* *}$ & $.45^{*}$ & $.51^{\prime \prime}$ & $.65^{* *}$ \\
\hline
\end{tabular}

Apesar do tamanho reduzido da amostra (26 participantes) os resultados são bastante satisfatórios, salientando-se o $r$ de .91 para o Factor II como o mais ele- 
vado. Os restantes coeficientes são também fortes (superiores a .80), à excepção do Factor $V$ com um coeficiente teste-reteste que se afasta dos restantes (.65).

Estes resultados satisfatórios ao nivel da fidelidade, encontram paralelo na análise da validade do $520 / 23$, já que se verificaram fortes correlações entre os seus resultados e o resultado total do MSO - versão reduzida, como se pode constatar no Quadro 6.

Salienta-se a elevada correlação de .84 entre o resultado total do $520 / 23$ e o do MSQ - versão reduzida, bem como as restantes correlações com os cinco factores. O Factor IV - Intrínseca apresenta o valor mais alto (.78), enquanto o valor mais baixo se verifica ao nível do Ambiente Físico (Factor II).

Quadro 6. Correlações entre o MSO - versão reduzida e o $\$ 20 / 23$

\begin{tabular}{l|c}
\hline & Total MSO (versão reduzida) \\
\hline S2023 Total & .84 \\
\hline Factor I - Supervisão & .77 \\
\hline Factor II - Ambiente Físico & .54 \\
\hline Factor III - Benefícios & .71 \\
\hline Factor IV - Intrínseca & .78 \\
\hline Factor V- Participação & .72 \\
\hline
\end{tabular}

Foi realizada ainda uma análise factorial exploratória, a fim de verificar a correspondência entre esta versão e a original no que concerne aos seus factores subjacentes.

Os 23 itens do $520 / 23$ foram alvo de uma análise das componentes principais, depois de uma verificação prévia da possibilidade de efectuar uma análise factorial à escala. Salienta-se em primeiro lugar que o tamanho da amostra se revelou adequado tendo em conta as recomendações de Pallant (2001) de cinco participantes por item. A exploração da matriz de correlações revelou resultados acima de .30 para quase todos os itens, à excepção de algumas correlações mais baixas (mas próximas de .30) envolvendo principalmente o item 15 (proximidade e frequência da supervisão) e o item 16 (forma como os supervisores avaliam as tarefas). O valor de Kaiser-Meyer-Olkin foi de .89, excedendo o valor recomendado de 6 (Kaiser, 1970, 1974, cit in Pallant, 2001) e o valor de Bartlett's Test of Sphericity atingiu a significância estatística $(p=.000)$.

A análise das componentes principais revelou a presença de cinco componentes com eigenvalues superiores a 1, explicando 51.42\%, 10.93\%, 5.83\%, 4.46\% e $4.44 \%$, respectivamente (num total de $77.08 \%$ ). A inspecção do screeplot revelou também uma quebra clara após a quinta componente. 
Para interpretar estas cinco componentes efectuou-se a rotação Varimax cujos resultados estão representados no Quadro 7. Salienta-se que alguns itens saturaram em mais que uma componente, mas foram organizados de acordo com a sua saturação mais forte com um dos factores.

Quadro 7. Estrutura factorial do $520 / 23$

\begin{tabular}{|c|c|c|c|c|c|}
\hline Itens & 1 & 2 & 3 & 4 & 5 \\
\hline 15. Proximidade e frequência da supervisão & .88 & & & & \\
\hline 14. Supervisão recebida & .83 & & & & \\
\hline 16. Forma como superiores avaliam tarefas & .81 & & & & \\
\hline 18. Apoio dos superiores & .78 & & & & \\
\hline 13. Relações pessoais com superiores & .75 & & & & \\
\hline 17. Tratamento com igualdade e justiça & .72 & & & & \\
\hline 8. Iluminação & & .86 & & & \\
\hline 9. Ventilação & & .85 & & & \\
\hline 7. Ambiente físico e espaço & & .83 & & & \\
\hline 10. Temperatura & & .81 & & & \\
\hline 6. Limpeza, higiene e saúde & & .75 & & & \\
\hline 3. Realizar tarefas que gosta & & & .70 & & \\
\hline 1. Trabalho por si mesmo & & & .66 & & \\
\hline 2. Realizar tarefas em que se destaca & & & .64 & & \\
\hline 19. Decidir autonomamente & & & .60 & & \\
\hline 20. Participar nas decisões da secção & & & & .77 & \\
\hline 21. Participar nas decisões do grupo & & & & .73 & \\
\hline 23. Negociação laboral & & & & .57 & \\
\hline 22. Legislação laboral & & & & .56 & \\
\hline 12. Progressão profissional & & & & & .81 \\
\hline 4. Salário & & & & & .71 \\
\hline 11. Formação & & & & & .66 \\
\hline 5. Objectivos metas e índices & & & & & .52 \\
\hline Eigenvalue & 11.83 & 2.51 & 1.34 & 1.03 & 1.02 \\
\hline \% de variância explicada & 51.42 & 10.93 & 5.83 & 4.46 & 4.44 \\
\hline
\end{tabular}

A interpretação desta estrutura factorial é consistente com a organização em cinco factores efectuada pelos autores do instrumento.

Observando o Quadro 7 é possível constatar que os itens 13, 14, 15, 16, 17 e 18 surgem associados à primeira componente, tal como surgem incluídos no Factor I - Supervisão, no estudo de construção do instrumento realizado Meliá e Peiró (1989a). O mesmo se verifica com a segunda componente, cujos itens (6 ao 10) se incluem no Factor II-Ambiente Físico como definido pelos autores do instrumento.

A terceira componente inclui os itens 1, 2, 3 e 19, assemelhando-se ao Factor IV Intrínseca que inclui também os itens 1, 2, 3 e ainda o 5, não incluindo o 19 (que na versão original se associa ao Factor $V$ - Participação). Também a componente 
quatro inclui itens que na versão original se encontram em dois factores: os itens 20 e 21 (Factor V - Participação) e itens 22 e 23 (Factor III - Benefícios).

Finalmente, a componente cinco inclui três itens do Factor III - Benefícios (4, 11 e 12) e ainda o item 5 do Factor IV - Intrínseca.

Apesar de alguns itens surgirem neste estudo associados a outras dimensões, a estrutura factorial organizada em cinco componentes é bastante consistente com a versão original do instrumento.

\section{Discussão e conclusão}

De acordo com Meliá et al. (1990) a satisfação profissional é um dos aspectos que mais tem captado o interesse dos psicólogos organizacionais. Esta centralidade do constructo encontra-se igualmente em investigações realizadas noutras áreas, incluindo a medicina, economia, industria, ciências sociais e educação (VanVoorhis \& Levinson, 2006). Tendo em conta que está directamente relacionada com o desempenho e motivação dos trabalhadores (Ahmadi \& Alireza, 2007), constituise um indicador de qualidade e desenvolvimento organizacional (Garcia-Ramos, Luján-López \& Martínez-Corona, 2007).

Neste estudo, os resultados relativos à satisfação com o trabalho, avaliada na questão incluída no Questionário de Caracterização Geral (numa escala de 4 pontos), revelam que os participantes se encontram relativamente satisfeitos com a sua situação laboral. Este resultado é confirmado pela cotação média obtida pelos participantes no S2O/23 e no MSO- - versão reduzida.

Os resultados obtidos nesta amostra de trabalhadores portugueses são bastante satisfatórios, comparando com os dados obtidos por O'Neill (2002, cit in VanVoorhis \& Levinson, 2006) que refere que apenas $51 \%$ dos trabalhadores americanos dizem estar satisfeitos com o seu trabalho. Manter níveis elevados de satisfação laboral traduz-se no aperfeiçoamento dos processos de trabalho e em consequência, na melhoria da produtividade (Garcia-Ramos, Luján-López \& Martínez-Corona, 2007). Embora, alguns investigadores (por exemplo, Brief, 1998; Fisher, 2003) defendam que não é a satisfação com o trabalho que faz aumentar a produtividade, mas a execução correcta de uma actividade que leva ao incremento da satisfação profissional. Independentemente do sentido de causalidade adoptado na compreensão da satisfação profissional, salienta-se que estes resultados são bastante animadores no panorama económico nacional (com base na amostra em estudo). São também resultados relevantes para os trabalhadores considerando a sua importância na procura de significado, propósito e satisfação em geral com 
a vida (Hagihara, Tarumi, Babazono, Nobutomo, \& Morimoto, 1998; Trott, 1996; cit in Robert, Young \& Kelly, 2006).

Outro aspecto a realçar, relaciona-se com o facto dos participantes se manifestarem mais satisfeitos (com base nos resultados do S2O/23) com a dimensão intrínseca da satisfação profissional e a possibilidade de participarem activamente no desenvolvimento da organização, revelando-se menos satisfeitos com os aspectos extrínsecos (ambiente físico, supervisão e benefícios). De acordo com a Pesquisa Europeia de Condições de Trabalho realizada em 2005, os trabalhadores portugueses estão em geral satisfeitos com as condições de trabalho, embora haja uma preocupação com os níveis de salário, aliás são os trabalhadores menos satisfeitos da União Europeia com o salário que recebem, tendo em conta o trabalho desempenhado (Portugal Diário, 2007).

No mesmo sentido, surgiram resultados mais elevados na dimensão intrínseca avaliada pelo MSO - versão reduzida. Estes resultados encontram paralelo noutras investigações, como por exemplo, no estudo de Garcia-Ramos, Luján-López e Martínez-Corona (2007) com profissionais de saúde onde a dimensão intrínseca foi a mais valorizada pelos trabalhadores. Também Seco (2000) refere que foi possivel observar que os trabalhadores de vários países (Bélgica, Inglaterra, Israel e EUA) referenciam a natureza interessante do trabalho como o factor mais importante. Em Portugal parecem igualmente existir indicadores que apontam para um valorização da dimensão intrínseca (Moreno, 1998; Seco, 2000; Vala, Bastos \& Catarro, 2000).

De facto, o trabalho assume uma importância central na vida do ser humano pelo desafio e sensação de utilidade que cria e não apenas pelas recompensas que acarreta como o salário e o estatuto social (Francès, 1984). Estes resultados vão ao encontro da teoria proposta em 1959 por Herzberg, Mausner e Snyderman que salienta a importância da dimensão intrínseca para o aumento da satisfação em geral com o trabalho, não esquecendo a influência dos aspectos extrínsecos na prevenção da insatisfação laboral.

Estas constatações lançam pistas no âmbito da intervenção psicológica em contextos organizacionais, sugerindo que é possivel aplicar estratégias para melhorar a motivação intrínseca dos trabalhadores, conduzindo a um maior esforço na realização das suas actividades, não negligenciando contudo, a motivação extrínseca que se não satisfeita pode produzir efeitos negativos no trabalho (Garcia-Ramos, Luján-López \& Martínez-Corona, 2007).

Nesta amostra, estes dados são reforçados pela análise das médias obtidas ao nível dos itens do $\mathrm{S}_{20 / 23}$, detectando-se maior satisfação com trabalho em si mesmo e satisfação mais baixa no que diz respeito às oportunidades de formação oferecidas pela organização. 
Srikonda (1999, cit in Hernandez \& Melo, 2003) refere que níveis elevados de satisfação estão relacionados precisamente (entre outros aspectos) com as possibilidades de formação e desenvolvimento da carreira. Em Portugal, a valorização da formação por parte das organizações não tem sido uma prática comum, à excepção da formação informal baseada numa aprendizagem rápida que visa apenas a preparação dos trabalhadores para a realização das suas tarefas (Parente, 1996). Aliás, segundo o inquérito sobre as condições de trabalho na União Europeia, realizado pela Fundação Europeia para a Melhoria das Condições de Vida e de Trabalho (em 1995/1996), os portugueses foram os trabalhadores que participaram menos (apenas 13\% enquanto a média europeia é de $38 \%$ ) em acções de formação profissional (Graça, 1999). Contudo, fomentar a aprendizagem no âmbito do processo produtivo na sua globalidade, de saberes individuais e colectivos, e de aspectos relativos à socialização, é crucial para as organizações que pretendem responder às exigências de competitividade (e até sobrevivência) no actual contexto económico e social.

A exploração da relação entre variáveis sócio-demográficas e satisfação com o trabalho, revelou algumas associações deste constructo com a idade e habilitações dos participantes. Os dados sugerem que os participantes mais novos estão menos satisfeitos com as condições do ambiente físico do que os restantes participantes. Também se verificou uma correlação positiva embora fraca entre a idade e o item 1 (trabalho em si mesmo) do S20/23. Sweeney, Hohenshil e Fortune (2002, cit in Spector, 1997) referem que numerosos estudos apontam diferenças entre grupos etários na satisfação com o trabalho, os resultados desses estudos geralmente mostram um aumento no nivel de satisfação com o trabalho com a idade (Spector, 1997) tal como se verificou nesta amostra, quer ao nivel dos aspectos extrínsecos (ambiente físico de trabalho), quer na sua dimensão mais intrínseca (trabalho em si mesmo).

Ao nível das habilitações também se verifica uma correlação positiva, desta feita com aspectos relacionados com a possibilidade de participação dos trabalhadores em decisões (nas suas tarefas, na sua equipa de trabalho e no seu departamento ou secção de trabalho) e no que concerne à igualdade e justiça no tratamento que recebem. De acordo com Lopes (2006) segundo algumas teorias, o trabalhador tem a opção de ampliar o seu capital humano por via da qualificação educativa e profissional, de forma a aumentar a sua produtividade. Possivelmente, as organizações que defendem estas perspectivas valorizam o papel dos trabalhadores mais qualificados na tomada de decisões revelando um tratamento mais justo e igualitário, a fim de potenciar os seus resultados produtivos. No entanto Berg (1971, cit in Lopes, 2006) reconhece a importância da escolaridade do trabalhador na fase do recrutamento mas defende que existe pouca evidência de que a escolaridade aumente a capacidade produtiva. 
Seria interessante em próximas investigações explorar os factores que poderão estar associados a estas diferenças nas faixas etárias e níveis académicos, como por exemplo, o tipo de vínculo laboral, o salário e tempo de permanência na organização, a fim de compreender as associações verificadas entre estas variáveis e a satisfação profissional.

A relação encontrada entre satisfação e sucesso profissional (questões incluídas no Questionário de Caracterização Geral) merece também suporte empírico adicional, nomeadamente no que concerne aos valores e preferências associados ao trabalho, tendo em conta que segundo Pryor (1981), o sucesso profissional se define em função destas duas características.

Estas questões relativas à satisfação geral e sucesso actual revelaram-se ainda correlacionadas com todos os itens do $\mathrm{S}_{2} \mathrm{O} / 23$ e seu resultado total. A possibilidade de avaliar a satisfação em geral com o trabalho com uma única questão é defendida por vários autores (como por exemplo, Scarpello \& Campbell 1983, cit in Wanous, Reichers \& Hudy, 1997) reduzindo substancialmente o tempo necessário para aplicação de instrumentos mais completos como o \$20/23. Mas como alertam Wanous, Reichers e Hudy (1997) é necessário explorar com mais pormenor esta possibilidade.

Salientam-se ainda as correlações mais elevadas entre estas duas questões do Questionário de Caracterização Geral e o Factor IV (Intrínseca), reforçando mais uma vez a importância desta dimensão ao nível da satisfação em geral e, desta feita, também ao nível do sucesso profissional. Relativamente a esta questão do sucesso, salienta-se que a amostra em estudo considera que actualmente tem algum sucesso profissional, o que constitui mais um dado positivo sobre os trabalhadores portugueses em estudo, nesta caracterização de carácter descritivo.

Na análise dos resultados relativos aos objectivos deste estudo, concluiu-se que o S2O/23 apresentou propriedades psicométricas ajustadas que aconselham a sua utilização em contexto português. Os elevados valores de consistência interna quer para a escala total (.95), quer para os cinco factores subjacentes (entre .84 - Factor IV e .94 - Factor I) apontam para uma consistência interna muito satisfatória do instrumento. Estes resultados são superiores aos reportados pelos autores do instrumento (.92 para a escala total e entre .76 e .89 para os cinco factores).

Comparando os resultados deste estudo com os que foram obtidos por Carlotto e Câmara (2008) na sua adaptação do instrumento à população brasileira, verifica-se mais uma vez que os resultados neste trabalho são superiores, no que concerne à consistência interna para a escala total (.91) e factores (superiores a .77). Os resultados do presente estudo ao nível da consistência interna apresentam-se 
ligeiramente superiores aos de Pocinho e Garcia (2008), corroborando as qualidades satisfatórias do $520 / 23$, em diferentes amostras de trabalhadores portugueses.

Apesar de não terem sido encontrados na literatura, dados sobre a estabilidade do instrumento, estes primeiros resultados verificados na população portuguesa são bastante animadores, tendo em conta as fortes correlações teste-reteste no intervalo temporal de aproximadamente um mês (à excepção do Factor $V$, que revelou uma correlação teste-reteste de .65 , resultado que deve ser confirmado em futuros estudos).

Ao nível da validade convergente os resultados são igualmente bastante positivos, tendo em conta que se verificaram fortes correlações (.84) entre os resultados do $\mathrm{S} 2 \mathrm{O} / 23$ e de outro instrumento que mede o mesmo constructo, o MSO - versão reduzida, salientando-se mais uma vez a relevância do Factor IV - Intrínseca na avaliação em geral da satisfação (considerando que obteve o valor mais elevado de correlação com o MSO - versão reduzida).

Ao nivel da estrutura factorial constata-se igualmente a adequação desta adaptação do instrumento ao contexto português, já que apresentou uma estrutura subjacente constituída por cinco factores, tal como na versão espanhola. Acresce-se o facto das duas primeiras componentes (Supervisão e Ambiente Físico) incluírem os mesmos itens que a versão original.

Na terceira componente (Intrínseca) verificou-se a inclusão dos respectivos itens $(1,2$ e 3) da versão original mais o item 19 - decidir autonomamente (que na versão original se inclui no Factor V - Participação) ao invés do item 5 - objectivos, metas e índices de produção. Relembra-se que este factor já havia revelado o valor mais baixo de consistência interna. Parece que estes participantes consideram que a possibilidade de tomar decisões relativas ao seu trabalho está associada à natureza das tarefas desempenhadas e não à sua possibilidade de participação nas decisões organizacionais em geral. Contudo, convém explorar se a tradução do item não estará a enviesar este resultado na análise factorial, ou se constitui apenas uma especificidade cultural do nosso país.

Neste estudo, os itens 20 e 21 (relativos à tomada de decisões do departamento e grupo de trabalho) 22 e 23 (cumprimento da legislação e negociação), surgem associados a uma mesma componente (a quarta), contrariamente ao que se verifica na versão original (incluindo-se respectivamente no Factor V - Participação e Factor III - Benefícios).

A última componente inclui, para além dos respectivos itens do Factor III - Benefícios (4, 11 e 12) o item 5 (que na versão original pertence à satisfação intrínseca, embora com uma posição menos estável na estrutura, como referem os auto- 
res). Este item parece ter sido interpretado pelos participantes como associado aos benefícios recebidos e não à natureza do trabalho em si. Esta relação entre objectivos, metas e índices de produção e recompensas é relativamente compreensivel tendo em conta que actualmente em Portugal esta opção tem vindo a disseminar-se nas organizações (principalmente nas multinacionais a operar no nosso país) por exemplo, através da negociação de prémios de produtividade (muito comum na banca) para compensar os trabalhadores mais competitivos (Diário de Notícias, 2006).

Estes dados resultantes da análise factorial exploratória, encontram alguma semelhança com os resultados obtidos por Carlotto e Câmara (2008), no seu estudo de adaptação do instrumento à população brasileira. Se agruparmos as componentes 1 e 4 numa única dimensão (incluindo todos os itens dos factores I e V e os itens 22 e 23 do factor III da versão original), encontramos paralelo com a dimensão da satisfação com relações hierárquicas definida por Carlotto e Câmara (2008), faltando apenas o item 19 - decidir autonomamente (que ainda assim saturou acima de .30 nesta componente 4). Por sua vez, a componente 2 inclui precisamente os itens do Factor II da versão original, tal como no estudo de Carlotto e Câmara (2008), que denominaram esta dimensão tal como os autores do instrumento, como satisfação com o ambiente físico de trabalho. Finalmente, se agruparmos numa mesma categoria as componentes 3 e 5 (itens do factor IV) exceptuando os itens 4, 11 e 12 do factor III da versão original que na versão brasileira foram retirados do instrumento por se considerarem problemáticos na saturação factorial, verificamos a dimensão da satisfação intrínseca no trabalho (excluindo o item 19 que na população portuguesa parece o mais problemático). Assim, parecem existir três elementos gerais (coerente com o modelo teórico de Locke, 1984 adoptado pelos autores do instrumento) na avaliação da satisfação com o trabalho utilizando o S2O/23: (1) aspectos relacionados com o próprio trabalho e o seu conteúdo; (2) condições e ambiente de trabalho; e (3) características da supervisão e direcção (Carlotto \& Câmara, 2008).

Esta nova estrutura factorial verificada para a população do Brasil encontra paralelismo na população portuguesa estudada (se organizarmos as componentes em três dimensões) pelo que deverá ser testada em próximas investigações, através de uma análise factorial de carácter confirmatório, tendo em conta que é preciso considerar que há sempre uma certa instabilidade na distribuição factorial, de acordo com a população estudada (Carlotto \& Câmara, 2008). Assim sendo, as especificidades culturais encontradas em contexto português constituem pistas para futuras investigações.

Os resultados obtidos neste estudo parecem-nos suficientemente encorajadores, podendo servir como ponto de partida para outros estudos que permitam 
o enriquecimento do conhecimento sobre a satisfação profissional em Portugal, nomeadamente no que concerne às qualidades métricas dos instrumentos utilizados na sua avaliação (mais concretamente o S2O/23), tendo em conta as limitações metodológicas deste trabalho, inerentes ao tamanho da amostra e à tradução do instrumento.

Que este contributo permita, em última análise, a discussão teórica sobre a satisfação profissional em Portugal e a sua avaliação, e indirectamente, impulsione a implementação de mudanças nas práticas organizacionais com vista à realização profissional dos seus trabalhadores e simultaneamente o desenvolvimento positivo da organização.

\section{Referências Bibliográficas}

Ahmadi, K. \& Alireza, K. (2007). Stress and Job Satisfaction among Air Force Military Pilots. Journal of Social Sciences, 3(3), 159-163.

Brief, A. (1998). Attitudes in and around organizations. Thousand Oaks, CA: Sage.

Carlotto, M. \& Câmara, S. (2008). Propriedades psicométricas do Questionário de Satisfação no Trabalho (S2O/23). Psico-USF, 13(2), 203-210.

Diário de Notícias (2006). Uma opção chamada prémios de produtividade. Consultado em Janeiro de 2010, http://dn.sapo.pt/inicio/interior.aspx?content_id=634392.

Ferreira, J. A., Fernandes, R., Haase, R. F. \& Santos, E. R. (2009). Minnesota Satisfaction Questionnaire - Short Form: estudo de adaptação e validação para a população portuguesa. Psychologica, 51, 251-281.

Field, H., Holley, W. \& Armenakis, A. (1978). Computerized Answer Sheets: What Effects on Response to a Mail Survey? Educational and Psychological Measurement, 38(3), 755-759.

Fisher, C. (2003). Why do lay people believe that satisfaction and performance are correlated? Possible sources of a commonsense theory. Journal of Organizational Behavior, 24(6), 753-777.

Francès, R. (1984). Satisfação no trabalho e no emprego. Porto: Rés Editora, Lda.

Garcia-Ramos, M., Luján-López, M. \& Martínez-Corona, M. (2007). Satisfacción laboral del personal de salud. Rev Enferm Inst Mex Seguro Soc, 15(2), 63-72.

Graça, L. (1999). Qualidade e Condições de Trabalho. Consultado em Janeiro de 2010, http:// www.ensp.unl.pt/lgraca/textos6.html.

Hernandez, J. \& Melo, F. (2003). O clima organizacional e a satisfação dos funcionários de um Centro Médico Integrado. Revista Psicologia: Organizações e Trabalho, 3(1), 11-26.

Herzberg, F., Mausner, B. \& Snyderman, B. (1959). The Motivation to Work. New York: John Wiley.

Hirschfeld, R. (2000). Does revising the intrinsic and extrinsic subscales of the Minnesota Satisfaction Questionnaire short form make a difference. Educational Psychology Measure, 60, 255-270.

Jewell, L., Beavers, K., Kirby, B. M., \& Flowers, J. (2001). Relationships between levels of job satisfaction expressed by North Carolina vocational agriculture teachers and their 
perceptions toward the agricultural education teaching profession. Journal of Agricultural Education, 31(1), 52-57.

Levinson, E. (1998). Stress, Burnout and Dissatisfaction in School Psychology. Consultado em Janeiro 2010, http://www.coe.iup.edu/emlevins/aspp2/index.htm

Locke, E. (1976). The nature and causes of job satisfaction, in M. Dunnette (Ed.) Handbook of Industrial and Organizational Psychology. Chicago: Rand McNally.

Lopes, R. (2006). Concepções Científicas e Pessoais sobre a Educação/Formação Profissional: Contributos para a Elaboração de um Modelo Teórico. Consultado em Janeiro de 2010, http://repositorium.sdum.uminho.pt.

Martinez-Tur, V., Peiró, J.M. \& Ramos, J. (2001) Calidad de Servicio y Satisfacción del Cliente [Service Quality and Customer Satisfaction] Ed. Síntesis. Madrid.

Meliá, J. \& Peiró, J. (1989a). La medida de satisfacción laboral en contextos organizacionales: El Cuestionario de satisfacción S20/23. Psicologemas, 5, 59-74.

Meliá, J.L., \& Peiró, J. M. (1989b). El Cuestionario de Satisfacción S10/12: Estructura factorial, fiabilidad y validez. Revista de Psicologia del Trabajo y de las Organizaciones, 4 (11), 179-187.

Meliá, J.L., Pradilla, J.F., Martí, N., Sancerni, M.D., Oliver, A., \& Tomás J.M. (1990). Estructura factorial, fiabilidad y validez del Cuestionario de Satisfacción S21/26: Un instrumento con formato dicotómico orientado al trabajo profesional. Revista de Psicologia Universitas Tarraconensis, 12(1/2), 25-39.

Moreno, J. (1998). Motivação de professores: estudo de factores motivacionais em professores empenhados. Revista Portuguesa de Educação, 11(1), 87-101.

Pallant, J. (2001). SPSS Survival Manual. Buckingham: Open University Press.

Parente, C. (1996). As empresas como espaço de formação. Consultado em Fevereiro de 2010, http://ler.letras.up.pt/uploads/ficheiros/1394.pdf

Pedro, N. \& Peixoto, F. (2006). Satisfação profissional e auto-estima em professores dos $2^{\circ}$ e $3^{\circ}$ ciclos do ensino básico. Análise Psicológica, 2(XXIV), 247-262.

Peiró, J. M. \& Tetrick, L. (2011) Occupational Health Psychology.In. Martin, P.R., Cheung, F.M. Knowles, M.C., Kyrios, M., Littlefield, L., Overmeir, J.B. \& Prieto, J.M. (Eds.) The IAAP Handkbook of Applied Psychology. Blackwell Publishing.

Pocinho, M. \& Garcia, J. (2008). Impacto psicosocial de la Tecnología de Información e Comunicación (TIC): tecnoestrés, daños físicos y satisfacción laboral. Acta Colombiana de Psicología, 11(2), 127-139.

Portugal Diário (2007). Portugueses com medo de perder emprego. Consultado em Janeiro de 2010, http://portalemprego.eu/noticia.php?noticialD $=134$.

Pryor, R. (1981). Interests and values as preferences: a validation of the Work Aspect Preference Scale. Australian Psychologist, 16(2), 258-272.

Robert, T., Young, J. \& Kelly, V. (2006). Relationships between adult worker's spiritual wellbeing and job satisfaction: a preliminary study. Counseling and Values, 50(3), 165.

Saane, N., Sluiter, J., Verbeek, J., \& Frings-Dresen, M. (2003). Reliability and validity of instruments measuring job satisfaction - a systematic review. Occupational Medicine, 53,191-200.

Seco, G. (2000). A satisfação na actividade docente. Tese de Doutoramento não publicada, Faculdade de Psicologia e de Ciências da Educação, Universidade de Coimbra.

Simões, A., Ferreira, J., Lima, M., Pinheiro, M., Vieira, C., Matos, A., \& Oliveira, A. (2000). O bem-estar subjectivo: Estado actual dos conhecimentos. Psicologia, Educação e Cultura, IV (2), 243-279. 
Spector, P. (1997). Job Satisfaction: Application, Assessment, Causes, and Consequences. Thousand Oaks, CA: Sage Publications.

Vala, J., Bastos, J. \& Catarro, M. (1983). Dimensões das motivações para o trabalho - um estudo empírico. Psicologia, IV (3 e 4), 251-260.

VanVoorhis, R. \& Levinson, E. (2006). Job satisfaction among school psychologists: a metaanalysis. School Psychology Quarterly, 21(1), 77-90.

Wanous, J., Reichers, A. \& Hudy, M. (1997). Overall Job Satisfaction: How Good Are SingleItem Measures? Journal of Applied Psychology, 82(2), 247-252.

Weiss, D. J., Dawis, R. V., England, G. W., \& Lofquist, L. H. (1967). Manual for the Minnesota Satisfaction Questionnaire (Minnesota Studies in Vocational Rehabilitation: XXII). Minneapolis: University of Minnesota, Industrial Relations Center Work Adjustament Project.

\section{Contribution to the psychometric study of the Portuguese version of the Cuestionario de Satisfacción Laboral S20/23}

Job satisfaction is understood through its dual role on organization productivity and employees achievement (Smith, 1998). The use of instruments to measure it in Portugal, has been the subject of several studies, such as the adaptation of the Cuestionario de Satisfacción Laboral S20/23 (Meliá \& Peiró, 1989) to Portuguese population carried out by Pocinho and García (2008).

This study is a further contribution to the study of the psychometric qualities of this instrument. The results on a sample of 136 Portuguese employees show that the questionnaire presents the adequate requirements of internal consistency (.95), test-retest reliability, and convergent validity (correlation of .84 with the Minnesota Satisfaction Questionnaire - Short Form of Weiss, Dawis, England, \& Lofquist, 1967). The factorial structure is consistent with the original version. Some issues to be explored in further investigations are also discussed, taking into account the limitations inherent to this study.

KEY-WORDS: job satisfaction; Cuestionario de Satisfacción laboral S20/23; psychometric properties; factor analysis

\section{Contribution à l'étude psychométrique de la version portugaise du Cuestionario de la Satisfacción Laboral S20/23}

La satisfaction au travail est comprise dans le double rôle de la productivité de l'organisation et de la réalisation des travailleurs (Smith, 1998). L'utilisation d'instruments pour l'évaluer dans un contexte national, a fait l'objet de certaines études, 
en soulignant l'adaptation à population portugaise du Cuestionario de Satisfacción Laboral S20/23 (Meliá \& Peiró, 1989) réalisée par Pocinho et García (2008).

Cette étude est une contribution supplémentaire à l'étude des qualités psychométriques de cet instrument. Les résultats d'un groupe de 136 travailleurs portugais montrent que le questionnaire représente les exigences appropriés au niveau de la cohérence interne (.95), stabilité coefficients et la validité convergente (corrélation de .84 avec le Minnesota Satisfaction Questionnaire - Short Form de Weiss, Dawis, England, \& Lofquist, 1967). La structure factorielle est compatible avec la version originale. Certains sujets sont encore en discussion pour être explorer dans de futures recherches, tout en tenant compte des limites inhérentes à cette étude.

MOTS-CLÉS: satisfaction au travail; Cuestionario de Satisfacción S20/23; caractéristiques psychométriques; analyse factorielle 